\title{
ACTH does not mediate divergent stress responsiveness in
}

rainbow trout

Tom G. Pottinger*, Toby R. Carrick

NERC Centre for Ecology and Hydrology, Windermere Laboratory, The Ferry House, Far

Sawrey, Ambleside, Cumbria LA22 OLP, United Kingdom

Running title: stress responsiveness and interrenal function

* Corresponding author. Tel: +44 (0)15394-42468; fax: +44 (0)15394-46914

E-mail address: tgp@ceh.ac.uk 


\begin{abstract}
Two lines of rainbow trout selected for high (HR) and low (LR) responsiveness to a standardised confinement stressor displayed a sustained divergence in plasma cortisol levels during a $3 \mathrm{~h}$ period of confinement (max.: HR: $167 \pm 13 \mathrm{ng} \mathrm{ml}^{-1}$; LR: $103 \pm 8 \mathrm{ng} \mathrm{ml}^{-1} ; P<$ 0.001). However, no significant difference in plasma ACTH levels was evident (max: HR: $153 \pm 9 \mathrm{pg} \mathrm{ml}^{-1}$; LR: $142 \pm 7 \mathrm{pg} \mathrm{ml}^{-1}$ ). Dexamethasone (DEX) was administered to HR and LR fish to block endogenous adrenocorticotropin (ACTH) release. Administration of a weight-adjusted dose of ACTH to the DEX-blocked fish elevated plasma cortisol levels to a significantly greater extent in $\operatorname{HR}\left(233 \pm 24 \mathrm{ng} \mathrm{ml}^{-1}\right)$ than LR $\left(122 \pm 14 \mathrm{ng} \mathrm{ml}^{-1}\right)$ fish $(P<$ 0.001). Plasma cortisol levels in DEX-blocked HR and LR fish after sham injection were low but also significantly different (HR: $6.7 \pm 1 \mathrm{ng} \mathrm{ml}^{-1}$; LR: $2.2 \pm 0.2 \mathrm{ng} \mathrm{ml}^{-1} ; P<0.001$ ). These results indicate that modulation of cortisol responsiveness to stressors in HR and LR fish resides, at least in part, downstream of the hypothalamic-pituitary axis.
\end{abstract}

Key words: Stress; rainbow trout; Oncorhynchus mykiss; cortisol; ACTH; dexamethasone; selective breeding 


\section{Introduction}

The potentially adverse effects of physical, chemical, and behavioural stressors on fish under aquaculture conditions are well understood. The performance of fish can be attenuated by stress via interference with growth, reproductive processes, and immunocompetence (Pickering, 1998). Complete elimination of potentially stressful aspects of the aquaculture process is impossible for economic and practical reasons. Therefore, modification of the sensitivity of aquacultured fish to unavoidable stressors has been considered as a potential strategy to alleviate the economic and welfare consequences of stress (Pottinger and Pickering, 1997; Pottinger, 2000).

Recent studies have demonstrated that the stress responsiveness of individual rainbow trout, measured as the magnitude of increase in blood cortisol levels following exposure to a standardised confinement stressor, is to a large extent an individual characteristic (Pottinger et al., 1992, 1994) with a moderate to high degree of heritability (Fevolden et al, 1999; Pottinger and Carrick, 2000) offering the prospect of selection for stress tolerant fish. However, it is not yet known at what site(s) within the hypothalamus-pituitary-interrenal (HPI) endocrine cascade selection for responsiveness operates.

The aim of this study was to investigate whether differences in the cortisol response to stress in two lines of rainbow trout selected for high or low responsiveness to confinement arise from differences within the hypothalamic/pituitary axis or from differences in interrenal function. This aim was addressed by measuring plasma ACTH levels in the two lines of fish during confinement and by the administration of ACTH to dexamethasone-blocked fish. 


\section{Materials and methods}

\subsection{High-responding $(H R)$ and low-responding (LR) fish}

Heritability of the magnitude of the plasma cortisol increase in response to a stressor is high in rainbow trout $\left(h^{2}=0.4-0.6\right.$; Fevolden et al., 1999; Pottinger and Carrick, 1999), which facilitated the production of two lines of fish with high (HR) or low (LR) responsiveness to stress. Fifteen HR and fourteen LR full-sib families of rainbow trout (Oncorhynchus mykiss) were generated from parents selected for high- or low-cortisol responsiveness to a standardised confinement stressor respectively. In brief, selection of the parents was achieved by transferring the individually tagged fish in groups from holding tanks (1000 l) to confinement tanks (50 1) for $3 \mathrm{~h}$ and determining the mean post-confinement levels of plasma cortisol for each fish over 5 episodes of confinement, carried out at monthly intervals. The fish were ranked on the basis of their individual mean cortisol response to confinement and progeny groups were generated from the fish displaying most divergence in responsiveness (Pottinger and Carrick, 1999). The six families from each of the HR and LR lines that consistently displayed the greatest divergence in responsiveness were identified.

\subsection{Measurement of plasma cortisol and ACTH levels in HR and LR fish during confinement}

Six fish from each of three of the most divergent HR (mean weight \pm SEM; $402 \pm 17 \mathrm{~g}, \mathrm{n}=$ 18) and LR families $(459 \pm 23 \mathrm{~g}, \mathrm{n}=18)$ were netted rapidly from their holding tank into bucket containing anaesthetic (2-phenoxyethanol; 1:2000 in lake water; Sigma-Aldrich). Blood samples were removed from the cuverian sinus using a syringe containing EDTA (1.5 $\mathrm{mg} \mathrm{ml}^{-1}$ blood) and aprotinin (3000 KU ml${ }^{-1}$ blood; Sigma-Aldrich). The samples were kept 
on ice until being centrifuged. Plasma was stored frozen $\left(-20^{\circ} \mathrm{C}\right)$. The fish were individually marked on the ventral surface using alcian blue dye (Sigma-Aldrich) administered with a Panjet needleless injector (Wright Dental Group), to allow their identification at subsequent sample points during the time-course study, and transferred to a 501 confinement tank supplied with a constant flow of lake water $\left(151 \mathrm{~min}^{-1}\right)$. Additional blood samples were taken from each fish, after anaesthetization, at $0.5,1,2$ and $3 \mathrm{~h}$ after the initial sample. At the final sample, after anaesthetization and blood sampling, the fish were killed by a blow to the head, weighed and measured. Plasma cortisol and ACTH levels were determined as described by Pickering et al. (1987) and Balm and Pottinger (1993) respectively.

\subsection{Evaluation of the relative sensitivity of $H R$ and LR fish to ACTH using dexamethasone} blockade of the pituitary-interrenal axis

Forty fish, twenty each from the two HR (mean weight \pm SEM; $860 \pm 39 \mathrm{~g}, \mathrm{n}=20$ ) and LR $(920 \pm 35 \mathrm{~g}, \mathrm{n}=20)$ families displaying greatest divergence in cortisol responsiveness to confinement, were netted from their holding tanks, anaesthetised (2-phenoxyethanol; 1:2000), and injected intraperitoneally with $1 \mathrm{mg} \mathrm{kg}^{-1}$ dexamethasone (Sigma-Aldrich) in ethanol:phosphate-buffered saline (PBS; $1: 3 ; 1 \mu \mathrm{g} \mu^{-1}$ ). LR fish were marked ventrally with alcian blue (Panjet) and all fish were transferred to a single holding tank. After 24 hours the fish were netted in groups, anaesthetised, and each fish was given an intraperitoneal injection of adrenocorticotropic hormone (ACTH, fragment 1-24; Sigma-Aldrich) in PBS at $45 \mu \mathrm{g} \mathrm{ml}^{-1}$, $0.5 \mathrm{ml} \mathrm{kg}^{-1}$. The fish were returned to their holding tank to recover and $2 \mathrm{~h}$ after ACTH administration were netted, anaesthetised, and blood sampled. Blood was kept on ice, centrifuged, and plasma was frozen until required for analysis. A second group of forty fish from each of the HR and LR families was treated similarly but following dexamethasone 
administration these were given injections of PBS only in order to control for endogenous production of ACTH during the experimental procedure.

\subsection{Statistical analysis}

The results were subjected to analysis of variance (ANOVA, Genstat 5, Lawes Agricultural Trust) with individual fish, sample time, and line (HR, LR) as factors for the time-course study, and line (HR, LR) and treatment (sham, ACTH-injected) for the dexamethasone blockade experiment. In both cases a plot of residuals against fitted values indicated that mean and variance were co-dependent. Therefore data were log-transformed prior to analysis. Significant differences between groups were determined using the estimated standard error of the differences between means, derived from the ANOVA.

\section{Results}

\subsection{Measurement of plasma ACTH levels in HR and LR fish during confinement}

Overall, plasma cortisol levels increased significantly with time following the onset of confinement $(P<0.001)$. Cortisol levels in the HR fish were significantly higher than cortisol levels in the LR fish at every time point, including the $0 \mathrm{~h}$ sample $\left(7.8 \pm 0.9 \mathrm{ng} \mathrm{ml}^{-1}\right.$ c.f. $4.2 \pm$ $1.0 \mathrm{ng} \mathrm{ml}^{-1} ; P<0.001$; Fig. 1b). The maximum difference between HR and LR fish was observed after $3 \mathrm{~h}$ when levels in the HR group were $167 \pm 13 \mathrm{ng} \mathrm{ml}^{-1}$ compared to $103 \pm 8 \mathrm{ng}$ $\mathrm{ml}^{-1}$ in the LR group $(P<0.001)$.

Blood ACTH levels also showed a significant increase with time $(P<0.001)$ during the period 
of confinement from a mean of $35 \pm 5 \mathrm{pg} \mathrm{ml}^{-1}$ (LR) and $31 \pm 5 \mathrm{pg} \mathrm{ml}^{-1}$ (HR) to a maximum of $142 \pm 7$ and $153 \pm 9 \mathrm{pg} \mathrm{ml}^{-1}$ after $2 \mathrm{~h}$ confinement (Fig. 1a). However, there was no statistically significant difference between ACTH levels in HR and LR fish overall, or at any time point.

\subsection{Evaluation of the relative sensitivity of $H R$ and LR fish to ACTH using dexamethasone} blockade of the pituitary-interrenal axis

Mean plasma cortisol levels in the two groups of dexamethasone-injected fish $2 \mathrm{~h}$ following ACTH administration were significantly different $(P<0.001)$, with HR fish displaying higher

mean levels $\left(233 \pm 24 \mathrm{ng} \mathrm{ml}^{-1}\right)$ than LR fish $\left(122 \pm 14 \mathrm{ng} \mathrm{ml}^{-1}\right.$; Fig. 2). In the dexamethasoneinjected fish that received only PBS (controls) blood cortisol levels were considerably lower, but a significant difference $(P<0.001)$ between HR and LR fish was nonetheless detected $(6.7$ \pm 1.0 c.f. $2.2 \pm 0.2 \mathrm{ng} \mathrm{ml}^{-1}$; Fig. 2).

\section{Discussion}

Plasma cortisol levels in HR and LR rainbow trout during $3 \mathrm{~h}$ of confinement displayed a degree of divergence which was similar to that previously observed with these lines of fish (Pottinger and Carrick, 1999, 2000). The difference in mean plasma cortisol levels between the two lines was sustained throughout the period of confinement indicating that selection had modified the absolute plasma levels attained during stress rather than the dynamics of the response. The elevation of plasma cortisol levels during stress in fish, as in other vertebrates, is attributed largely, though not exclusively, to the direct stimulation of steroidogenesis in the interrenal by the pituitary peptide adrenocorticotropin (ACTH; Mommsen et al., 1999). 
Plasma levels of ACTH both before and during confinement in the present study were comparable with those reported elsewhere for rainbow trout (Sumpter et al., 1986; Balm and Pottinger, 1995). Increases in plasma ACTH precede changes in plasma cortisol levels but this relative difference in the rate of change of the two hormones is most pronounced during the early phase of the stress response (2 - 10 mins; Sumpter et al., 1986) and was therefore not evident in the present study in which the first sample was collected 30 mins after the start of confinement. No statistically significant differences in plasma ACTH levels between the HR and LR fish were apparent at any point during the time-course. The similarity of plasma ACTH levels in the HR and LR lines suggested that the disparity in cortisol levels could not arise from differences in pituitary corticotrope function between the lines. Instead, functional divergence in the HPI axis appears to occur downstream of the pituitary. By isolating the interrenal from stimulation by endogenous $\mathrm{ACTH}$, and stimulating cortisol production with a standardised exogenous dose of ACTH, it was confirmed that divergence in cortisol responsiveness in the HR and LR fish arises via interrenal or post-interrenal mechanisms.

Blockade of the pituitary-interrenal axis in trout by the corticosteroid analogue dexamethasone (DEX) has previously been demonstrated (Pickering et al., 1987). It is likely that DEX mimics the negative feedback effects of cortisol on the secretion of ACTH and/or corticotropin releasing hormone $(\mathrm{CRH})$ by interacting with specific corticosteroid receptors in the brain, hypothalamus and/or pituitary (Allison and Omeljaniuk, 1998; Teitsma et al., 1998). In the present study the administration of DEX was successful in preventing the substantial stress-induced elevation of plasma cortisol levels which would be expected to occur consequent to handling and injection of PBS. Plasma cortisol levels in DEX-blocked HR and LR fish after sham injection were in both cases $<10 \mathrm{ng} \mathrm{ml}^{-1}$, a level normally considered to be typical of unstressed salmonids (Barton and Iwama, 1991), but there was a 
significant difference between the two lines with plasma levels in DEX-blocked HR fish significantly higher than those in DEX-blocked LR fish. When a weight-adjusted dose of ACTH was administered to the DEX-blocked fish the subsequent elevation of plasma cortisol was almost two-fold greater in the HR than LR fish.

These observations indicate that the difference in responsiveness between HR and LR fish arises from alteration of interrenal or post-interrenal factors. These might include the sensitivity of the interrenal tissue to ACTH, the steroidogenic capacity of the interrenal tissue, interrenal tissue mass, or differences in clearance of cortisol. This interpretation of the results is supported by consideration of studies in mammalian and avian lines divergent for stress responsiveness. In Japanese quail (Coturnix coturnix japonica) selectively bred over 6 or 7 generations for high serum corticosterone responses to immobilization adrenocortical cells displayed similar basal rates of corticosterone production in vitro to cells from random-bred birds (Carsia et al., 1988). However, adrenocortical tissue from the high-responding birds produced significantly more corticosterone in response to either ACTH or cAMP. Coupled with higher adrenal weights in high-responding birds than in random-bred individuals these authors concluded that greater adrenocortical responsiveness to ACTH was a major factor in the enhanced corticosterone response observed in the high-stress line. Similar results were reported for white leghorn domestic fowl (Gallus domesticus) in which strain differences in adrenocortical cell sensitivity to ACTH were observed (Carsia and Weber, 1986). In five inbred rat strains differences in corticosterone response to immobilization between the strains were attributed to differential sensitivity of both the pituitary to $\mathrm{CRF}$ and adrenal to ACTH (G. $\therefore$ mez et al., 1996). In pigs also, differences in adrenal sensitivity have been suggested to underlie variation in stress responsiveness between individuals. Marked differences in adrenocortical responsiveness to administered ACTH between pigs (Hennessy et al., 1988; 
Kanitz et al., 1999) have been linked to differences in adrenocortical volume and density of ACTH receptors (Zhang et al., 1993). We are aware of no similar studies on other fish species.

In conclusion, the difference in the plasma cortisol stress response observed in two lines of rainbow trout selected for divergent responses to a standardised stressor is not mediated directly by the hypothalamic-pituitary axis. This observation is consistent with previous studies on lines of animals that display divergent stress responsiveness. Further work is necessary to assess the contribution made to divergence of stress responsiveness in trout by differences in the biosynthetic capacity of the interrenal tissue, in ACTH receptor density, in interrenal tissue mass and in the clearance/metabolism of cortisol.

\section{Acknowledgements}

This study has been carried out with financial support from the Commission of the European Communities, Agriculture and Fisheries (FAIR) specific RTD programme CT95-152

"Selective breeding for stress tolerance in aquacultured fish" and from the Natural Environment Research Council of the UK.

\section{References}

Allison, C. M., Omeljaniuk, R. J., 1998. Specific binding sites for $\left[\mathrm{H}^{3}\right]$ dexamethasone in the hypothalamus of juvenile rainbow trout, Oncorhynchus mykiss. Gen. Comp. Endocrinol. 110, 2-10. 
Balm, P. H. M., Pottinger, T. G., 1993. Acclimation of rainbow trout (Oncorhynchus mykiss) to low environmental $\mathrm{pH}$ does not involve an activation of the pituitary - interrenal axis but evokes adjustments in branchial ultrastructure. Can. J. Fish. Aquat. Sci. 50, $2532-2541$.

Balm, P. H. M., Pottinger, T. G., 1995. Corticotrope and melanotrope POMC-derived peptides in relation to interrenal function during stress in rainbow trout (Oncorhynchus mykiss). Gen. Comp. Endocrinol. 98, 279-288.

Barton, B. A., Iwama, G. K., 1991. Physiological changes in fish from stress in aquaculture with emphasis on the response and effects of corticosteroids. Ann. Rev. Fish Dis. 1, 326.

Carsia, R. V., Weber, H., 1986. Genetic-dependent alterations in adrenal stress response and adrenocortical cell function of the domestic fowl (Gallus domesticus). Proc. Soc. Exp. Biol. Med. 183, 99-105.

Carsia, R. V., Weber, H., Satterlee, D. G., 1988. Steroidogenic properties of isolated adrenocortical cells from Japanese quail selected for high serum corticosterone response to immobilization. Dom. Anim. Endocrinol. 5, 231-240.

Fevolden, S.-E., Rped, K. H., Fjalestad, K. T., Stien, J., 1999. Post-stress levels of lysozyme and cortisol in adult rainbow trout (Oncorhynchus mykiss); heritabilities and genetic correlations. J. Fish Biol. 54, 900-910. 
G $\therefore$ mez, F., Lahmame, A., de Kloet, E. R., Armario, A., 1996. Hypothalamic-pituitaryadrenal response to chronic stress in five inbred rat strains: differential responses are mainly located at the adrenocortical level. Neuroendocrinol. 63, 327-337.

Hennessy, D. P., Stelmasiak, T., Johnston, N. E., Jackson, P. N., Outch, K. H., 1988. Consistent capacity for adrenocortical response to ACTH administration in pigs. Am. J. Vet. Res. 49, 1276-1283.

Kanitz, E., Otten, W., Nurnberg, G., Brussow, K. P., 1999. Effects of age and maternal reactivity on the stress response of the pituitary-adrenocortical axis and the sympathetic nervous system in neonatal pigs. Anim. Sci. 68, 519-526.

Mommsen, T. P., Vijayan, M. M., Moon, T. W., 1999. Cortisol in teleosts: dynamics, mechanisms of action, and metabolic regulation. Rev. Fish Biol. Fish. 9, 211-268.

Pickering, A. D., 1998. Stress responses of farmed fish. In: Black, K. D., Pickering, A. D. (Eds.), Biology of Farmed Fish. Sheffield Academic Press, Sheffield, pp. 222-255.

Pickering, A. D., Pottinger, T. G., Sumpter, J. P., 1987. On the use of dexamethasone to block the pituitary-interrenal axis in the brown trout, Salmo trutta L. Gen. Comp. Endocrinol. 65, 346-353.

Pottinger, T. G., 2000. Genetic selection to reduce stress in animals. In: Moberg, G. P., Mench, J. A. (Eds.), The Biology of Animal Stress. Basic Principles and Implications 
for Animal Welfare. CABI Publishing, Wallingford, pp. 291-308.

Pottinger, T. G., Carrick, T. R., 1999. Modification of the plasma cortisol response to stress in rainbow trout by selective breeding. Gen. Comp. Endocrinol. 116, 122-132.

Pottinger, T. G., Carrick, T. R., 2000. Indicators of reproductive performance in rainbow trout Oncorhynchus mykiss (Walbaum) selected for high and low responsiveness to stress. Aquacult. Res. 31, 367-375.

Pottinger, T. G., Pickering, A. D., 1997. Genetic basis to the stress response: selective breeding for stress-tolerant fish. In: Iwama, G. K., Pickering, A. D., Sumpter, J. P., Schreck, C. B. (Eds.), Fish Stress and Health in Aquaculture. Cambridge University Press, Cambridge, pp. 171-193.

Pottinger T. G., Pickering A. D., Hurley M. A., 1992. Consistency in the stress response of individuals of two strains of rainbow trout, Oncorhynchus mykiss. Aquaculture 103, 275-289.

Pottinger T. G., Moran T. A., Morgan J. A. W., 1994. Primary and secondary indices of stress in the progeny of rainbow trout (Oncorhynchus mykiss) selected for high and low responsiveness to stress. J. Fish Biol. 44, 149-163.

Sumpter, J. P., Dye, H. M., 1986. The effects of stress on plasma ACTH, $\alpha-\mathrm{MSH}$, and cortisol levels in salmonid fishes. Gen. Comp. Endocrinol. 62, 377-385. 
Teitsma, C. A., Anglade, I., Bailhache, T., Tujague, M., Toutirais, G., Ducouret, B., Kah, O., 1998. Distribution of glucocorticoid receptors in the brain of rainbow trout (Oncorhynchus mykiss): Possible relationships with the neuroendocrine systems controlling reproduction. Bull. Fr. P $\Lambda$ che Piscic. 350-351, 597-607.

Zhang, S.-H., Hennessy, D. P., McCauley, I., Cranwell, P. D., 1993. Adrenocortical ACTH receptors in pigs of differing in vivo response to adrenocorticotropin. Comp. Biochem. Physiol. 104A, 43-49. 


\section{Captions to Figures}

Figure 1. The time-course of changes in (a) plasma ACTH and (b) plasma cortisol levels in LR $(\bullet)$ and HR $(O)$ rainbow trout subjected to a $3 \mathrm{~h}$ period of confinement. Each point is the mean \pm SEM, $\mathrm{n}=18$. Significant differences between HR and LR fish at each time point are denoted by $* P<0.05, * * P<0.01, * * * P<0.001$.

Figure 2. Plasma cortisol levels in LR and HR rainbow trout $2 \mathrm{~h}$ following intraperitoneal injection with either phosphate-buffered saline (PBS; $0.5 \mathrm{ml} \mathrm{kg}{ }^{-1}$; sham-injected) or adrenocorticotropic hormone in PBS (45 $\mu \mathrm{g} \mathrm{ml}^{-1}, 0.5 \mathrm{ml} \mathrm{kg}^{-1}$; ACTH-injected). All fish were injected $24 \mathrm{~h}$ previously with dexamethasone $\left(1 \mathrm{mg} \mathrm{kg}^{-1}\right.$ in ethanol:PBS; $\left.1: 3 ; 1 \mu \mathrm{g}^{-1}\right)$. Each value is the mean \pm SEM $(n=20)$. Significant differences between HR and LR fish are depicted by $* * * P<0.001$. 

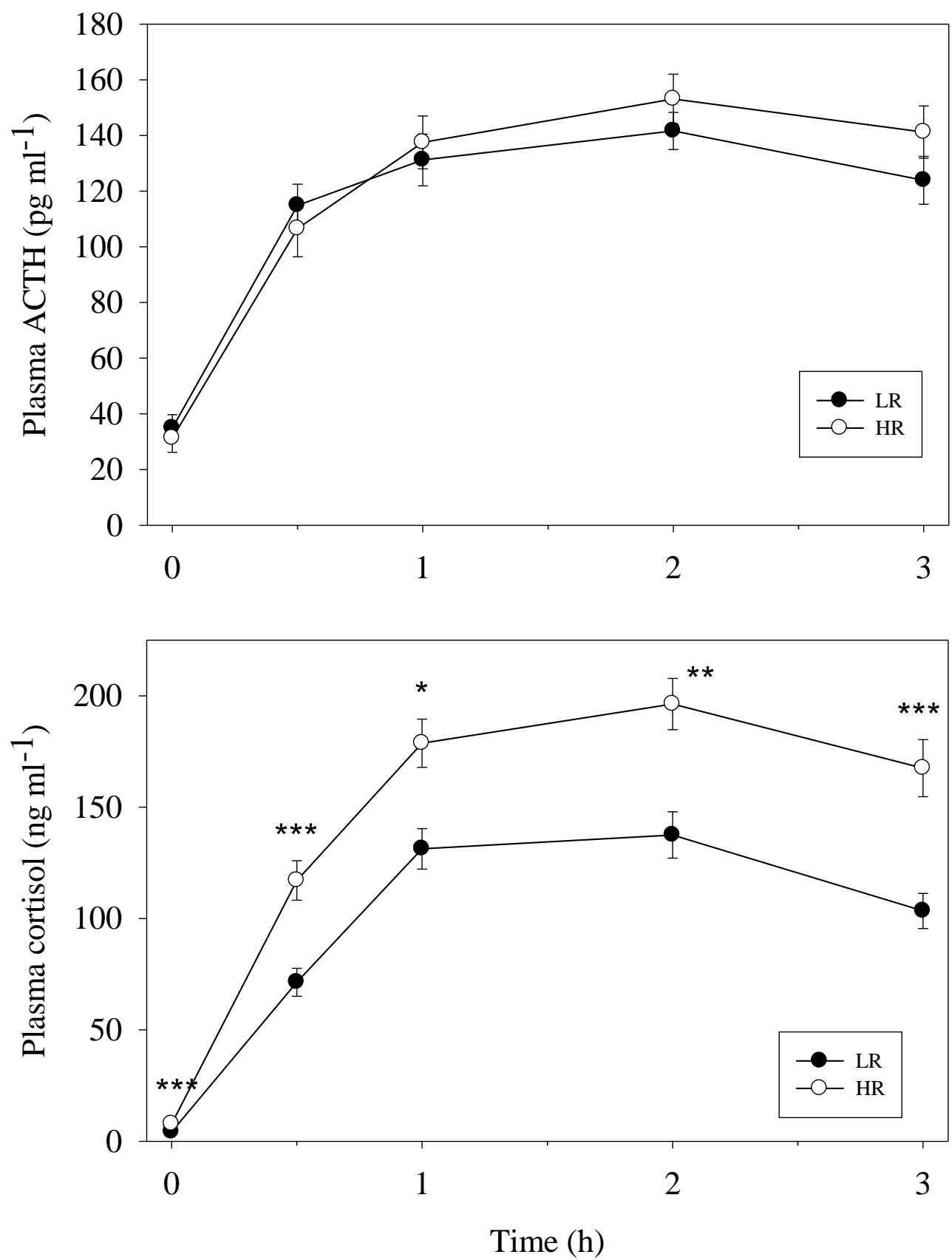

Pottinger \& Carrick, Figure 1. 


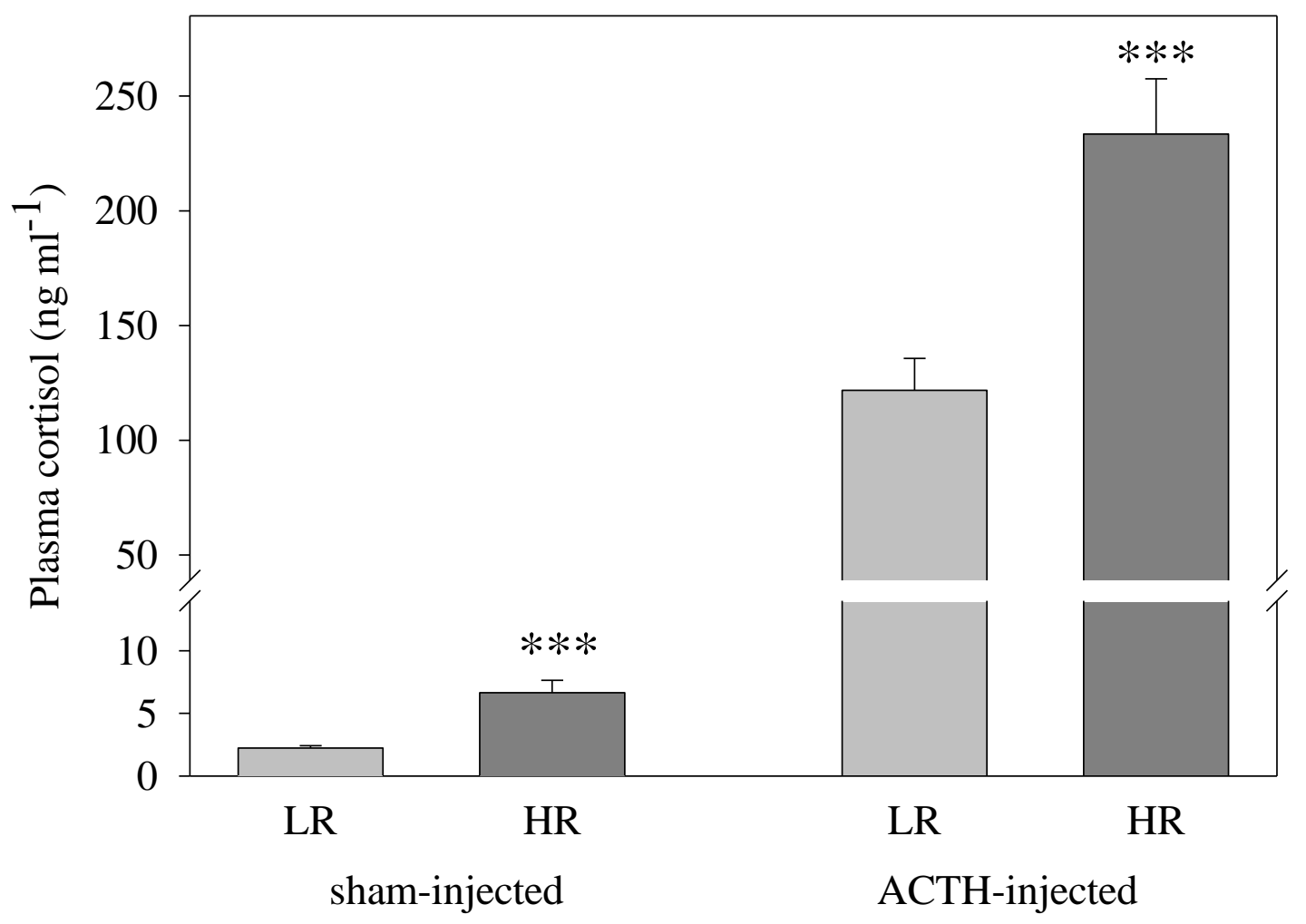

Pottinger \& Carrick, Fig. 2 